\title{
PENGARUH GAYA KEPEMIMPINAN DAN LINGKUNGAN KERJA FISIK TERHADAP KINERJA PEGAWAI PUSKESMAS PASAR BARU RANTAU PANJANG KECAMATAN TABIR
}

\author{
Misra Yeni R, Sukma Wariyadi \\ Program Studi Manajemen Fakultas Ekonomi \\ Universitas Muara Bungo
}

\begin{abstract}
ABSTRAK
Tujuan penelitian ini adalah untuk mengetahui seberapa besar pengaruh gaya kepemimpinan dan lingkungan kerja fisik terhadap kinerja pegawai Puskesmas Pasar Baru Rantau Panjang Kecamatan Tabir secara parsial maupun simultan. Metode yang digunakan dalam penelitian ini adalah metode deskriptif- kuantitatif.Penelitian deskriptif adalah metode yang menggambarkan suatu data yang akan baik oleh peneliti sendiri maupun kelompok, sementara metode kuantitatif adalah metode mengunakan metode analisis kuantitatif, dimana hasil kuantitatif disajiakan dalam bentuk angka-angka yang kemudian dijelaskan dan diinterprestasikan dalam suatu uraian. Sampel berjumlah 60 orang yang merupakanpegawaipuskesmas pasar baru rantau panjang kecamatan tabir

Hasil penelitian ini, uji parsial variabel Gaya kepemimpinan (X1) didapatkan nilai $t_{\text {hitung }}$ positif sebesar $(3,684)>t_{\text {tabel }}(2,002)$, nilai signifikansi $0,001<0,050$, dan memiliki pengaruh sebesar 0,439 atau 43,9\% sehingga $\mathrm{H}_{0}$ ditolak dan $\mathrm{H}_{\mathrm{a}}$ diterima,dan variabel Lingkungan Kerja Fisik $\left(\mathrm{X}_{2}\right)$ didapatkan nilai $\mathrm{t}_{\text {hitung }}$ positif sebesar $(2,154)>$ $t_{\text {tabel }}(2,002)$, nilai signifikansi $0,035<0,050$, dan memiliki pengaruh sebesar 0,274 atau 27,4\% sehingga Secara parsial variabel Gaya kepemimpinan dan Lingkungan Kerja Fisik berpengaruh positif dan signifikan terhadap kinerja pegawai.

Uji simultan. Berdasarkan output Anova diketahui Bahwa nilai $\mathrm{F}_{\text {hitung }}$ positif sebesar 11,153 > Ftabel sebesar 3,160, nilai signifikansi $0,001<0,050$, sehingga $\mathrm{H}_{0}$ ditolak dan $\mathrm{H}_{\mathrm{a}}$ diterima, sehingga Secara simultan varibel Gaya Kepemimpinan (X1) dan Lingkungan Kerja Fisik (X2) berpengaruh positif dan signifikan terhadap kinerja (Y) pegawai. Berdasarkan output Model Summary didapat nilai $R$ Square 0.256 atau $25,6 \%$.. sedangkan sisanya sebesar $74,4 \%$ dipengaruhi oleh faktor lainya yang tidak diteliti dalam penelitian ini.
\end{abstract}

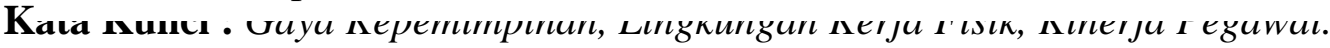

\section{PENDAHULUAN}

Kemajuan perusahaan atau organisasi tentunya didukung oleh kinerja karyawan. Seseorang dapat dikatakan mempunyai kinerja yang baik, manakala mereka dapat melaksanakan pekerjaan dengan baik, artinya mencapai sasaran atau menurut standar yang ditentukan dengan penilaian kinerja, dengan kata lain akan mendorong karyawan untuk bersaing memperoleh penghargaan, bonus atau dipromosikan kejabatan yang lebih baik.

Pemimpin harusbisa memberikan wawasan, membangkitkan kebanggaan, serta menumbuhkansikap hormatdan kepercayaan dari bawahannya. Pemimpinyangefektif adalahpemimpin yang mengakui kekuatan-kekuatan penting yang terkandung dalamindividu. Setiap individu mempunyai kebutuhan dan keinginan yang berbeda-beda. Setiap 
individu mempunyaitingkatkeahlian yang berbeda-bedapula.Pemimpin harus fleksibel dalam memahami segala potensi yang dimiliki olehindividu dan berbagai masalah yang dihadapi oleh individu tersebut. Denganmelakukan pendekatan tersebut pemimpin dapat menerapkan segala peraturandan kebijakan organisasi serta melimpahkan tugas dan tanggung jawab dengantepat. Hal ini sejalan dengan usaha untuk menumbuhkan komitmen organisasidari diri karyawan. Sehingga pemimpin nantinya dapat meningkatkan kepuasankaryawan terhadap pekerjaan serta dapat meningkatkan kinerja karyawandengan lebih efektif. Gaya kepemimpinan, mengandung pengertian sebagai suatu perwujudan tingkah laku dari seorang pemimpin, yang menyangkut kemampuannya dalam memimpin bawahannya. Perwujudan tersebut biasanya membentuk suatu pola atau bentuk tertentu. Pengertian gaya kepemimpinan yang demikian ini sesuai dengan pendapat dari beberapa ahli diantaranya menurut Kartono, (2008) Gaya kepemimpinan adalah sifat, kebiasaan, tempramen, watak dan kepribadian yang membedakan seorang pemimpin dalam berinteraksi dengan orang lain..kemampuan mempengaruhi orang lain agar bersedia bekerja sama untuk mencapai tujuan yang telah ditetapkan dengan cara berbagai kegiatan yang akan dilakukan ditentukan bersama antara pimpinan dan bawahan.

Menurut Sedarmayanti (2012) Lingkungan kerja fisik adalah semua yang terdapat disekitar tempat kerja yang dapat mempengaruhi pegawai baik secara langsung maupun tidak langsung.

Menurut mangkunegara (2009) kinerja adalah hasil kera secara kualitas dan kuantitas yang dicapai oleh seorang pegawai dalam melaksanakan tugasnya sesuai dengan tanggung jawab yang diberikan kepadanya. Adapun data kepegawaian puskesmas pasar baru sebagai berikut:

\begin{tabular}{|c|l|c|c|c|c|c|}
\hline \multirow{2}{*}{ NO } & \multirow{2}{*}{ JENIS KETENAGAAN } & \multirow{2}{*}{ JUMLAH } & \multicolumn{4}{|l|}{ STATUS KEPEGAWAIAN } \\
\cline { 4 - 7 } & & & PNS & \multicolumn{1}{l|}{ PTT } & \multicolumn{1}{l|}{ TKD } & TKS \\
\hline 1 & PUSKESMAS & & & & & \\
\hline & Dokter & 2 & 2 & 0 & 0 & 0 \\
\hline & SKM & 3 & 2 & 0 & 1 & 0 \\
\hline & Farmasi & 1 & 0 & 0 & 1 & 0 \\
\hline & Perawat & 18 & 3 & 0 & 5 & 10 \\
\hline & Bidan & 23 & 5 & 0 & 7 & 11 \\
\hline & Kesling & 0 & 0 & 0 & 0 & 0 \\
\hline & Perawat gigi & 1 & 0 & 0 & 0 & 1 \\
\hline & Analis & 1 & 0 & 0 & 0 & 1 \\
\hline & Lcpk & 1 & 1 & 0 & 0 & 0 \\
\hline & Sma & 3 & 1 & 0 & 1 & 1 \\
\hline 2 & Pustu & & & & & \\
\hline & Perawat & 1 & 1 & 0 & 0 & 0 \\
\hline 3 & Poskesdes & & & & & \\
\hline & Akbid & & 1 & 0 & 0 & 0 \\
\hline
\end{tabular}


Jurnal Manajemen Sains volume 1, Nomor 1, Januari 2021

\begin{tabular}{|c|l|c|c|c|c|c|}
\hline 4 & Polides/bides & & & & & \\
\hline & Akbid & 6 & 4 & 0 & 1 & 1 \\
\hline & JUMLAH & 61 & 20 & 0 & 16 & 25 \\
\hline
\end{tabular}

Sumber :Laporan Puskesmas Pasar Baru Tahun 2018.

Untuk membuat pegawai bekerja untuk organisasi pemimpin harus membuat limgkungan kerja puskesmas lebih kekeluargaan, kondusif, dan memberikan rasa nyaman kepada pegawai. Semua itu harus di tunjang dengan sarana dan prasarana yang memadai.

Menurut pengamatan sementara peneliti, di Puskesmas Pasar Baru sendiri mempunyai lingkungan fisik maupun non fisik cukup memadai, akan tetapi belum sempurna. Masih kurang lengkapnya peralatan pada bagian pelayanan kesehatan dan perkantoran seperti kurangnya pengadaan alat pemeriksaan pasien, jumlah computer, pokesdes, finger print, mobil ambulan, mushala, penerangan yang nimin dibeberapa ruangan, suhu udara yang cukup hangat waktu siang karena terbatasnya alat pendingin ruangan, ruang kerja yang cukup sempit sehingga membuat sulit bergerak, belum adanya tenaga keamanan (satpam), dan lain sebagainya dan pada akhirnya menyebabkan kinerja pegawai tidak maksimal. Dari hasil wawancara yang dilakukan peneliti masih terdapat komplain, diantaranya masih ada yang mendapati keterlambatan dalam pembuatan surat rujukan.Dalam hal ini peran kepemimpinan sangat diperlukan dengan selalu menjaga komunikasi yang baik antara pegawai dengan pimpinan maupun antara sesama pegawai. Selain itu lingkungan kerja baik fisik maupun non fisik didalam suatu organisai sangat penting untuk diperhatikan oleh pemimpinnya.

Berdasarkan uraian latar bekang di atas maka penulis tertarik untuk melakukan penelitian dengan judulPengaruh Gaya Kepemimpinan
Dan Lingkungan Kerja Fisik Terhadap Kinerja Pegawai Pada Puskesmas Pasar Baru Rantau Panjang Kecamatan Tabir.

\section{Gaya Kepemimpinan}

Gaya kepemimpinan, mengandung pengertian sebagai suatu perwujudan tingkah laku dari seorang pemimpin, yang menyangkut kemampuannya dalam memimpin bawahannya. Perwujudan tersebut biasanya membentuk suatu pola atau bentuk tertentu. Menurut Kartono, (2008) Gaya kepemimpinan adalah sifat, kebiasaan, tempramen, watak dan kepribadian yang membedakan seorang pemimpin dalam berinteraksi dengan orang lain..kemampuan mempengaruhi orang lain agar bersedia bekerja sama untuk mencapai tujuan yang telah ditetapkan dengan cara berbagai kegiatan yang akan dilakukan ditentukan bersama antara pimpinan dan bawahan.

\section{Lingkungan Kerja Fisik}

Menurut Sedarmayanti ( 2012 ) Lingkungan kerja fisik adalah semua yang terdapat disekitar tempat kerja yang dapat mempengaruhi pegawai baik secara langsung maupun tidak langsung.Sedangkan Menurut Nitisemito (2002) menyatakan bahwa Lingkungan Kerja fisik adalah segala sesuatu yang ada disekitar pekerja dan dapat mempengaruhi dirinya dalam menjalankan tugas-tugas yang dibebankan.

Dari beberapa definisi diatas dapat diambil kesimpulan bahwa Lingkungan Kerja fisik dapat mempengaruhi pekerja baik secara langsung ataupun tidak langsung.

Kinerja

Kinerja dalam organisasi merupakan jawaban dari berhasil atau 
tidaknya tujuan organisasi yang telah ditetapkan. Suatu organisasi selalu digerakkan oleh sekelompok orang yang berperan aktif untuk mencapai tujuan yang ingin dicapai dari organisasi tersebut. Tujuan organisasi tentunya tidak akan tercapai jika kinerja pegawainya tidak maksimal.Menurut mangkunegara (2009) kinerja adalah hasil kerja secara kualitas dan kuantitas yang dicapai oleh seorang pegawai dalam melaksanakan tugasnyasesuai dengan tanggung jawab yang diberikan kepadanya.

Dari pendapat diatas menggambarkan bahwa kinerja pegawai dan kinerja organisasi memiliki keterkaitan yang sangat erat, tercapainya tujuan organisasi tidak bisa dilepaskan dari sumber daya yang dimiliki oleh organisasi yang digerakkan atau dijalankan pegawai yang berperan aktif sebagai pelaku dalam upaya mencapai tujuan organisasi.

\section{METODOLOGI PENELITIAN}

Metode yang digunakan dalam penelitian ini adalah metode deskriptifkuantitatif.Penelitian deskriptif adalah metode yang menggambarkan suatu data yang akan baik oleh peneliti sendiri maupun kelompok, sementara metode kuantitatif adalah metode mengunakan metode analisis kuantitatif, dimana hasil kuantitatif disajiakan dalam bentuk angka-angka yang kemudian dijelaskan dan diinterprestasiakan dalam suatu uraian. ( sugiyono, 2017). Adapun teknik pengambilan sampel yang digunakan dalam penelitian ini adalah MetodePurposive Sampling yaitu salah satu metode sampling non rondom, dimana peneliti menentukan pengambilan sampel dengan cara menetapkan ciri-ciri khusus yang sesuai dengan tujuan penelitian sehingga diharapakan dapat menjawab permasalahan penelitian. Adapun sampel dalam penelitian ini berjumlah 60 orang. Angka 60 orang diperoleh dari jumlah pegawai sebanyak 61 orang dikurangi kepala puskesmas 1 orang. Kepala puskesmas tidak dijadikan sampel karena bagian dari variabel penelitian.

\section{HASIL PENELITIAN DAN PEMBAHASAN \\ Hasil Uji t (Parsial)}

Uji t dalam penelitian ini dilakukan dengan tingkat signifikansi $\alpha=0,05$. Sementara nilai $t_{\text {tabel }}$ pada $\alpha=0,05$ (uji dua sisi) dengan derajat kebebasan atau degree of freedom (df) $\mathrm{n}-\mathrm{k}$ dimana $\mathrm{n}=$ banyak sampel dan $\mathrm{k}=$ banyaknya variabel bebas dan terikat, maka 60- $3=57$ diperoleh $t_{\text {tabel }}$ sebesar 2,002.

\begin{tabular}{|c|c|c|c|c|c|c|c|c|c|}
\hline \multicolumn{10}{|c|}{ Coefficients $^{\mathrm{a}}$} \\
\hline \multirow{2}{*}{\multicolumn{2}{|c|}{ Model }} & \multicolumn{2}{|c|}{$\begin{array}{l}\text { Unstandardized } \\
\text { Coefficients }\end{array}$} & \multirow{2}{*}{\begin{tabular}{|c|}
$\begin{array}{l}\text { Standardiz d } \\
\text { Coefficients }\end{array}$ \\
Beta \\
\end{tabular}} & \multirow[b]{2}{*}{$\mathrm{t}$} & \multirow[b]{2}{*}{ Sig. } & \multicolumn{3}{|c|}{ Correlations } \\
\hline & & B & Std. Error & & & & Zero-order & Partial & Part \\
\hline \multirow[t]{3}{*}{1} & (Constant) & 6.569 & 7.055 & & .931 & d.356 & & & \\
\hline & Gaya Kepemimpinan & .432 & .117 & 422 & 3.684 & .001 & 472 & 439 & .414 \\
\hline & Lingkungan Kerja Fisik & .240 & .111 & .247 & 2.154 & .035 & .332 & .274 & .242 \\
\hline
\end{tabular}

Sumber : Output SPSS (olah data)

Berdasarkan tabel di atas dapat dijelaskan sebagai berikut :

a. Hasil uji $t$ untuk variabel Gaya Kepemimpinan $\left(\mathrm{X}_{1}\right)$

Berdasarkan hasil pengolahan data uji parsial, variabel Gaya Kepemimpinan $\left(\mathrm{X}_{1}\right)$ didapatkan nilai $t_{\text {hitungpositif sebesar }}$ $(3,684)>t_{\text {tabel }}(2,002)$, nilai signifikansi
$0,001<0,050$, dan memiliki pengaruh sebesar 0,439 atau 43,9\%. Sehingga dalam penelitian ini variabel Gaya Kepemimpinan secara parsial berpengaruh postif dan signifikan terhadap kinerja Pegawai. Artinya jika Gaya Kepemimpinan dari seorang pemimpin semakin baik, maka akan semakin 
meningkat pula kinerja pegawai pada Puskesmas Pasar Baru Rantau Panjang Kecamatan Tabir.

b. Hasil uji t untuk variabel Lingkungan Kerja Fisik $\left(\mathrm{X}_{2}\right)$

Berdasarkan hasil pengolahan data uji parsial,variabel Lingkungan Kerja Fisik $\left(\mathrm{X}_{2}\right)$ didapatkan nilai $t_{\text {hitung }}$ positif sebesar $(2,154)>t_{\text {tabel }}(2,002)$,nilai signifikansi $0,035<0,050$, dan memiliki pengaruh sebesar 0,274 atau 27,4\%, sehingga $\mathrm{H}_{0}$ ditolak dan $\mathrm{H}_{\mathrm{a}}$ diterima. Sehingga dalam penelitian ini variabel Lingkungan Kerja Fisiksecara parsialberpengaruh positif dan signifikan terhadap kinerja Pegawai.
Artinya jika Lingkungan Kerja Fisik semakin baik, maka akan semakin meningkat pula kinerja pegawai pada Puskesmas Pasar Baru Rantau Panjang Kecamatan Tabir.

\section{Hasil Uji F (simultan)}

Uji $F$ dalam penelitian ini dilakukan dengan tingkat sigifikansi $\alpha=$ 0,05 . Sementara nilai $f_{\text {tabelpada }} \alpha=0,05 \mathrm{df}$ $1(\mathrm{k}-1)$ atau 3-1 = 2, dan df $2(\mathrm{n}-1)$ atau 60 $-3=57$ (n adalah jumlah kasus atau atau responden dan $\mathrm{k}$ adalah jumlah variabel bebas dan terikat), diperoleh $F_{\text {tabel }}$ sebesar 3,160 .

\begin{tabular}{|c|c|c|c|c|c|c|}
\hline \multicolumn{7}{|c|}{ ANOVA $^{\mathrm{a}}$} \\
\hline \multicolumn{2}{|r|}{ Model } & \multirow{2}{*}{$\frac{\text { Sum of Squares }}{164.531}$} & \multirow{2}{*}{$\frac{\mathrm{Df}}{2}$} & \multirow{2}{*}{$\begin{array}{c}\text { Mean Square } \\
82.266\end{array}$} & \multirow{2}{*}{$\frac{F}{11.153}$} & \multirow{2}{*}{$\frac{\text { Sig. }}{.000^{\mathrm{b}}}$} \\
\hline 1 & Regression & & & & & \\
\hline & Residual & 420.452 & 57 & 7.376 & & \\
\hline & Total & 584.983 & 59 & & & \\
\hline \multicolumn{7}{|c|}{ a. Dependent Variable: Kinerja } \\
\hline \multicolumn{7}{|c|}{ b. Predictors: (Constant), Lingkungan Kerja Fisik, Gaya Kepemimpinan } \\
\hline
\end{tabular}

\section{Sumber : Output SPSS (olah data)}

Berdasarkan output Anova didapatkan nilai $\mathrm{F}_{\text {hitung }}$ positif sebesar11,153 $>$ Ftabel sebesar 3,160 , nilai signifikansi $0,000<0,050$, Sehingga $\mathrm{H}_{0}$ ditolak dan $\mathrm{H}_{\mathrm{a}}$ diterima. Maka dapat disimpulkan bahwa varibel Gaya Kepemimpinan (X1) dan Lingkungan Koefisien Determinasi $\left(\mathbf{R}^{2}\right)$

\begin{tabular}{|c|c|c|c|c|}
\hline \multicolumn{5}{|c|}{ Model Summary } \\
\hline Model & $\mathrm{R}$ & $\mathrm{R}$ Square & Adjusted R Square & Std. Error of the Estimate \\
\hline 1 & $.530^{\mathrm{a}}$ & .281 & .256 & 2.71594 \\
\hline
\end{tabular}

Sumber : Output SPSS (olah data)

Kerja Fisik (X2) secara simultan berpengaruh positif dan signifikan terhadap kinerja (Y) pegawai pada Puskesmas Pasar Baru Rantau Panjang Kecamatan Tabir.

Berdasarkan output Model Summary di atas dapat dilihat nilai $R$ Squaresebesar 0.256 atau

25,6\%. Besarnya nilai tersebut menunjukkan proporsi pengaruh yang dapat dijelaskan oleh variabel Gaya Kepemimpinandan Lingkungan Kerja Fisik secara bersama-sama terhadap besarnya variasi (naik turun) variabel terikat. Dimana variabel terikat $(\mathrm{Y})$ dapat dijelaskan oleh kedua variabel bebas sebesar $25,6 \%$, sedangkan sisanya sebesar $74,4 \%$ dipengaruhi oleh dimensi lain diluar penelitian.

\section{PENUTUP}

Kesimpulan 
Berdasarkan hasil penelitian dan pembahasan pada bab sebelumnya, maka dapat ditarik kesimpulan sebagai berikut :

1. Variabel Gaya Kepemimpinan secara parsial berpengaruh postif dan signifikan terhadap kinerja Pegawaipada Puskesmas Pasar Baru Rantau Panjang Kecamatan Tabir

2. Variabel Lingkungan Kerja Fisik secara parsial berpengaruh positif dan signifikan terhadap kinerja Pegawai pada Puskesmas Pasar Baru Rantau Panjang Kecamatan Tabir

3. Varibel Gaya Kepemimpinan dan Lingkungan Kerja Fisik secara simultan berpengaruh positif dan signifikan terhadap kinerja pegawai pada Puskesmas Pasar Baru Rantau Panjang Kecamatan Tabir

\section{Saran}

Berdasarkan kesimpulan diatas penulis memberikan saran sebagai berikut :

1. Disarankan kepada pimpinan

Puskesmas agar dapat meningkatkan kemampuan mengendalikan bawahansehingga dapat mengakomodir semua bentuk aktivitas pegawai dan Puskesmas Pasar Baru Rantau Panjang Kecamatan Tabir.

2. Bagi puskesmas Penerangan di bebeapa ruangan agar dapat itingkatkan oleh pihak puskesamas Pasar Baru Rantau Panjang Kecamatan Tabir, agar selalu nyaman dan tidak menghambat suatu pekerjaan sehingga dapat meningkatkan kinerja pegawai.

3. Para peneliti selanjutnya yang akan mengkaji lebih dalam tentang penelitian yang sama diharapkan agar penelitian ini dapat menjadi salah satu informasi yang bisa digunakan untuk penelitian selanjutnya.
Adri Agustiningrum (2012) Mengenai Pengaruh Gaya Kepemimpinan Dan Motivasi Terhadap Kinerja Pegawai Di Sekretariat Daerah.

Aditia, 2015.

Afner Rerung P (2015) Pengaruh Gaya Kepemimpinan Dan Lingkungan Kerja Terhadap Kinerja Karyawan Pada Rumah Sakit Umum Daerah Kota Makassar

Arep, Ishak Dan Hendri, Tanjung. (2002). Manajemen Sumber Daya Manusia.Jakarta: Universitas Trisakti.

Anwar Prabu,Mangkunegara (2005). Perilaku Dan Budaya Organisasi, Pt.Rafika Aditama, Bandung.

Dharma, Surya. 2004. Manajemen Kinerja, Falsafah, Teori Dan Penerapannya.Pustaka Pelajar: Yogyakarta

Desler, Gary. 2006. Manajemen Personalia. Erlangga : Jakarta.

Ghozali Imam, 2013. Aplikasi Analisis Multivariate Dengan Program Imb Spss 21 Update Pls Regresi. Semarang. Badan Penerbit Universitas Diponegoro.

Hartatik, Indah Puji. 2014. "Mengembangkan Sdm”. Jogjakarta: Laksana

Hadari, Nawawi. (2006). Kepemimpinan Mengefektifkan Organisasi. Yogyakarta: Gadjah Mada University Press.

Junaidi

(http://junaidichaniago.wordpress.com), 2010

Kartono, (2008) Pemimpin Dan Kepemimpinan. Jakarta: Raja Grafindo 
Mangkunegara, 2009 evaluasi kinerja sumber daya manusia, refika aditama, bandung.

Mahardika kawannto, (2016)

Miftah, Thoha. (2006). Kepemimpinan Dalam Manajemen. Jakarta: Raj Grafindo Persada.

Nadmudin 2017. Skripsi Fakultas Ekonomi Universitas Muara Bungo

Nitisemito, A. S. (2002). Manajemen Personalia, Edisi Revisi. Jakarta: Ghalia.

Ngalim, Purwanto. (2005). Administrasi Dan Supervisi Pendidikan. Bandung: Remaja Rosdakarya.

Nurkolis. (2006). Manajemen Berbasis Sekolah. Jakarta: Grasindo.

Nitisemito, A. S. (2002). Manajemen Personalia, Edisi Revisi. Jakarta: Ghalia

Pangabean. S, Mutiara. (2004). Manajemen Sumber Daya Manusia. Ghalia Indonesia : Bogor.

Rivai, Veithzal.Et. Al. (2012). Pemimpin Dan Kepemimpinan Dalam Organisasi. Jakarta. Pt Raja Grafindo Persada

Reza Amelia ( 2013). Pengaruh Budaya Organisasi Dan Stres Kerja Terhadap Kinerja Karyawan Melalui Kepuasan Kerja Srbagai Variabel Intervening (Studi Pada Bank Mandiri Cabang Padang). Jurnal Penelitian Manajemen

Sedarmayanti. (2007). Sumber Daya Manusia Dan Produktivitas Kerja. Mandar Maju: Bandung

(2012). Sumber Daya Manusia Dan Produktivitas Kerja. Mandar Maju: Bandung
Soetjipto, Budi W. (2004). Paradigma Baru Manajemen Sumber Daya Manusia. Yogyakarta: Amara Books.

Simamora, Hendry. 2004. Manajemen Sumber Daya Manusia. Stie. Ykpn:Jogjakarta.

Sugiyono, 2013. Metode Mengelola Marketing Mix Terhadap Kepuasan Konsumen Hotel Amaris Surabaya. Jurnal Manajemen Perhotelan. Fakultas Bisnis Vol 1. No 2.

2015. Metode Penelitian Kuntitatif Dan Kualitatif. Bandung: Cv. Alfabeta. Wursanto. (2009). Manajemen Kinerja. Pt Rajagrafindo Persada: Jakarta. 